Fakiri, F. el, Foets, M., Rijken, M.

Health care use by diabetic patients in the Netherlands: patterns and predicting factors.

Diabetes Research and Clinical Practice: 61, 2003, p. 199-209

\begin{tabular}{|c|c|}
\hline Postprint Version & 1.0 \\
\hline Journal website & http://www.sciencedirect.com \\
\hline Pubmed link & $\begin{array}{l}\text { http://www.ncbi.nlm.nih.gov/entrez/query.fcgi? } \mathrm{cmd}=\text { Retrieve\&db=pubmed\&dop } \\
\mathrm{t=}=\text { Abstract\&list_uids=12965110\&query } \mathrm{hl}=20 \text { \&itool=pubmed_docsum }\end{array}$ \\
\hline DOI & $10.1016 / \mathrm{S} 0168-8227(03) 00116-5$ \\
\hline
\end{tabular}

* Corresponding author. At the time of the research: Netherlands Institute for Health Services Research, Utrecht, Netherlands. Tel.: +31-10-408-8555; fax: +31-10-408-9094. E-mail address: elfakiri@bmg.eur.nl (F. El Fakiri).

1 At the time of the research: Netherlands Institute for Health Services Research, Utrecht, Netherlands.

\title{
Health care use by diabetic patients in the Netherlands: patterns and predicting factors
}

\author{
F. EL FAKIRI ${ }^{\mathrm{A},{ }^{*}}$, M. FOETS $^{\mathrm{A}, 1}$, M. RIJKEN ${ }^{\mathrm{B}}$ \\ a Department of Health Policy and Management, Erasmus Medical Centre, P.O. Box 1738, 3000 DR \\ Rotterdam, Netherlands \\ b Netherlands Institute for Health Services Research, Utrecht, Netherlands
}

\begin{abstract}
Aims: Diabetic patients require care from a variety of health care providers, but little is known about their actual use of health care. Aims of this study were to (1) obtain information on health care use by diabetic patients in the Netherlands, (2) distinguish patterns of health care utilisation among these patients, and (3) develop insight into the factors predicting these patterns. Method: Data on 388 diabetic patients were extracted from a nationally representative database of patients with chronic disease. Data on health care utilisation and background variables were collected in 1998 by means of a survey. Patients' GPs registered information about medical diagnosis, illness duration and comorbidity. Analysis included descriptive statistics, as well as cluster and logistic analysis. Results: Diabetic patients use a wide range of services, but large differences exist. Four patterns of health care utilisation could be distinguished: a pattern of low consumption, one of moderate consumption with a central role for internal medicine, one of more extensive diabetes care consumption, and one of high medical and home care consumption. Type 1 diabetes appeared to be an important determinant of the moderate, mainly internal medicine pattern and the more extensive diabetes care pattern. The pattern of high medical and home care was not predicted by diabetes type, but by the presence of comorbidity and by poor self-rated health. Conclusion: Despite the fact that diabetic patients use a wide range of health care services, there seems to be a problem of under utilisation, especially among type 2 diabetic patients.
\end{abstract}

\section{INTRODUCTION}

As in many countries, the prevalence of both type 1 and 2 diabetes in the Netherlands is increasing, along with the burden on health care [1-3]. Prevention of complications, which diabetes brings in the course of time, and retardation of their progression requires good control (glycaemic, lipids, blood pressure) by means of diet, exercise and eventually medication [4-7].

In the Netherlands, the vast majority of the population is covered by health insurance: below a certain income level, there is public insurance; above this level, people have private health insurance. There 
are no major differences in the coverage of both insurance types. Some health care services, such as hospital admissions and dietetic advice, are covered for everyone by national insurance (AWBZ).

Almost the total population is registered in a general practice and the general practitioner is the gatekeeper to most other health care services. Ultimately, he decides whether a patient is referred to secondary care. Since the general practitioner thus is charged with an important part of diabetes care in the Netherlands, the Dutch College of General Practitioners has developed the so-called 'Standaard Diabetes Type II'. It contains guidelines for screening, diagnosis and treatment, including education, glycaemic control, nutrition, hypoglycaemia medication, treatment of risk factors for cardiovascular disease, and regular control. These guidelines also include recommendations for consultation or referral to other health care providers [8].

Little is known about the extent to which diabetic patients actually consult health care providers. Although diabetes mellitus is one of the most frequently studied chronic diseases, most research focuses on its epidemiology, complications, on the ways patients cope with the disease and on the assessment of specific outcome measures such as glycaemic control, cardiovascular risk factors and complications. Because of their complex health care needs, it is also necessary to have insight into the total picture of health care use of diabetic patients and into factors contributing to differences in health care utilisation.

Some studies describe differences in the use of health care services by diabetic and non-diabetic patients, all indicating increased use of most services by diabetic patients [9-16]. Other studies investigated differences in health care use by diabetic patients. Under utilisation has been registered among elderly patients [17]. The use of services is somewhat lower by ethnic minority groups [18]. An overrepresentation of women among high consumers has been reported $[9,19]$. Panser et al. found that age modified by the effect of gender was the strongest risk factor for hospitalisation in patients with type 2 diabetes, while the presence of complications such as coronary heart disease, retinopathy and persistent proteinuria were also significant risk factors [20]. The use of dietetic services is related to gender, disease duration and the use of insulin [21]. Another study showed that nearly one third of the diabetic patients had never visited an ophthalmologist [14]. Type 1 diabetic patients use more physician services than type 2 patients [15]. Patients taking insulin were more likely to have an annual eye examination and foot examination than those who were not [16].

We may conclude that research on health care use among diabetic patients has limitations: many studies focus on a restricted number of health services and take into account a limited number of predicting factors. Only two studies, both from the United States have determined the amount of care received by diabetic patients. A study by Engelgau et al. showed that the majority of diabetic patients (72-94\%) see a GP at least once a year, and that ophthalmologists and optometrists were the most commonly visited specialists. About one fifth had a hospital stay in a 1-year period [22]. In another study by Beckles et al. $72 \%$ of the diabetic patients visited a health care provider at least once a year, $61 \%$ had their feet inspected at least once and $61 \%$ received an eye examination through dilated pupils [23]. This paper addresses the following research questions:

1. Which health care services do diabetic patients in the Netherlands use?

2. Which patterns of health care utilisation can be distinguished among diabetic patients?

3. Which factors predict these patterns of health care utilisation?

\section{METHODS}

\subsection{Patients}

Data for this study were collected using the framework of the Dutch 'Panel of Patients with Chronic Diseases' (PPCD), a study designed to provide information relevant for Dutch policy with respect to the consequences of somatic chronic disease, defined as irreversible diseases or diseases with a duration of at least 1 year, irrespective of the specific diagnosis. Chronic psychiatric disease, mental retardation and dementia were excluded. The study supplies core data on the health status, the use of health care services and the quality of care as perceived by the patients. The panel was set up on request of The Dutch Fund of Chronic Diseases, the Ministry of Health and the Dutch Health Inspectorate. During the first stage of the study six measurements had been planned in a 3-year period. Patients were selected from the patient records of a representative sample of 56 Dutch general practitioners in the Netherlands. In the case of more than one chronic disease, inclusion was based on 
the longest lasting chronic disease, the so-called index disease. Other chronic diseases were also registered, and considered as co-morbidity. Thus, co-morbidity in this study includes both chronic diseases that can be considered as complications of diabetes and chronic diseases that are unrelated to diabetes.

This study consists of two sub-samples. First, a generic sample, of 2487 patients was made. This group is representative of patients nationally with chronic somatic diseases, irrespective of the specific diagnosis. This generic sample was completed with an additional sample of 813 patients, in order to provide the opportunity for specific analyses for disease groups with high prevalence, such as diabetes. An attrition rate of $35 \%$ was expected after 3 years, based on a longitudinal study among rheumatoid arthritis patients by Smith and Wallston [24]. The generic sample can be considered as a random sample, since selection took place as follows. On the basis of a pilot study [25], we estimated that on average $10 \%$ of the total patient list of a Dutch general practitioner suffers from a somatic chronic disease, as defined above. On this basis, and given the mean size of a GP list, it was necessary to take random samples of $36 \%$ of the patients on each list, in order to form a gross sample of 5000 patients, and since we expected a non-response of $50 \%$. The GPs, assisted by a field worker, selected all patients with a somatic chronic disease from these samples. Whether the participating patients are representative of the target group is difficult to establish, because no data are available on the composition of the target group. The only information we have, are data on the disease and health status registered by the GPs on all the selected patients, irrespective of participation: these indicate very little differences [26].

Sample size for the selected disease groups, was based upon a power analysis, whereby the primary outcome measure was perceived quality of care of the general practitioner, as measured by the Quotequestionnaires, a validated instrument currently used in the Netherlands [27]. In order to detect a small to moderate $(\mathrm{d}=0.25)$ change in perceived quality of care, with an alpha $=0.05$ (two sided) and a power of $P=0.80$, power calculation indicated that at least 250 patients per disease group were necessary at the start of the study [28]. Using an estimated non-response of 50\%, the sample size was doubled: 500 patients per disease group.

On the basis of the pilot study, we did not expect that there would be sufficient diabetic patients in the general sample. So, additional selection took place. This additional selection of diabetes patients, as well as of the other disease groups also was carried out by the GP assisted by a field worker. These patients were selected from the remaining patients on the lists of the participating GPs.

Ultimately 388 patients with diabetes mellitus gave informed consent. Of these, 298 patients were included in the generic part of the sample, 90 in the additional sample.

Inclusion in the study is based upon a medical diagnosis. Other selection criteria were: aged 15 years or older, being non-institutionalised, being informed of the diagnosis, not being terminally ill, being mentally able to participate and a sufficient mastery of the Dutch language.

\subsection{Data}

Most PPCD data are collected by means of written structured questionnaires. For this study, data collected in 1998 were used. In addition, the participating GPs recorded a limited amount of data on health status. The following data were used in this study:

- Health care use was measured using the procedures of the Netherlands Health Interview Survey, in order to guarantee valid measurement [29]. Patients indicated whether or not they had used health care services during the last year. All available services were included: the general practitioner, medical specialists, allied health care, home care, hospital stay, social welfare, complementary medicine, and finally also mental health care, since patients suffering from chronic somatic disease may experience psychosocial consequences of their condition. Regarding the general practitioner, patients also reported the number of contacts. Concerning the use of medication, patients reported the use of prescribed medication during the last 2 weeks.

- Three types of independent factors were included, according to the well known framework of Andersen, designed to explain differences in the use of health care services [30]:

- Indicators of health status: the diagnosis of inclusion in the study (index disease: type 1 or 2 diabetes) and the presence of comorbidity were registered by the GP and classified according to the International Classification of Primary Care [31]. In addition, the GP provided the date of diagnosis on the basis of which illness duration was calculated. Furthermore, two health 
status indicators were included in the questionnaire: physical disability, assessed by the OECD long-term disability indicator [32], and perceived health, a single-item question 'In general, how do you perceive your health?' with five answering categories: excellent, very good, good, fair, and poor.

- So-called predisposing factors including gender, age and educational level.

- So called enabling factors: type of health care insurance (private, public), income level and availability of social support were included. Availability of social support was measured by the presence of other adults in the household (persons aged 18 or older).

\subsection{Statistical analysis}

In order to describe the study sample and the use of health care services, separate analyses were conducted for type 1 and 2 diabetes. Differences between type 1 and 2 patients were tested by means of Chi-square $\chi^{2}$-tests and $t$-tests for independent samples. When available, comparable figures for the Dutch population are presented (unpublished data, provided by Statistics Netherlands on request of the authors).

In order to investigate patterns of health care utilisation, a $k$-means cluster analysis (QUICK CLUSTER Procedure) was conducted [33]. This procedure, which is based on Euclidian distances, consists of dividing patients into clusters such that every patient belongs to only one cluster. This analysis was performed with the use of several health care services being the clustering variables and including the total group of diabetic patients.

In order to investigate determinants of the patterns of health care use identified in this way, multinomial logistic regression analysis was used, with cluster membership being the dependent variable [34]. All possible explaining factors included in this study were entered together as independent variables; categorical variables were treated as factors and continuous variables as covariates. A main-effects model was specified containing the covariate and factor main effects.

\section{RESULTS}

\subsection{Characteristics of the study population}

Table 1 presents a number of characteristics of the 134 patients with type 1 and 254 patients with type 2 diabetes. Whether a patient was classified as type 1 or 2 diabetes, was decided by the general practitioner, sometimes after consultation with a medical specialist. This distribution according to diabetes type does not correspond to the distributions usually found in general populations, where type 2 diabetes is by and large most prevalent. This is due to the additional sampling. We asked the GPs to select relatively more type 1 diabetes patients, in order to assure that separate analyses for both types were possible.

\section{[ TABLE 1 ]}

About half of the patients were male, half female in both groups. The mean age of patients with type 1 diabetes was 50, and with type 2, 65 years. The groups differed by education level: a large number of type 2 patients received no more than low secondary education. The groups did not differ with respect to household income and health care insurance type. Fourteen percent had a household income lower than $\mathrm{t} 840$, which is considered as the 'social minimum' for households with children. A majority ( $75 \%$ ) of the patients lived together with at least one adult.

The mean time post-diagnosis was 14.5 years in type 1 patients and 6.5 years in type 2 patients. The groups were comparable concerning the presence of physical disability, self-rated health and comorbidity. Of the 70 type 2 diabetic patients with co-morbidity, 49 suffered from one other disease, 21 suffered from two or more other diseases. Of the 29 type 1 diabetic patients, 23 suffered from one other disease, six suffered from two or more other diseases. Among the co-morbid conditions, cardiovascular disease was most prevalent, especially in type 2 diabetes (36 patients), followed by diseases of the musculoskeletal system (12 patients), lung diseases (six patients), and eye diseases (four patients). Cardiovascular diseases were also most prevalent as co-morbidity in type 1 (nine patients), followed by respiratory diseases (five patients) and by musculoskeletal diseases (four patients). 


\subsection{Use of health care services}

Table 2 shows that almost all patients visited their GP during the last year, regardless of diabetes type. Type 2 diabetic patients visited their GP more frequently than type 1 patients: the mean number of GP contacts per year is 4.3 (S.D.=4.5) for type 1 patients and $5.7(\mathrm{~S} . \mathrm{D} .=5.0)$ for type 2 patients $(t(356)=-2.57, P=0.01)$. Apart from consulting their GP, $16.5 \%$ of diabetic patients did not consult any other health care provider.

\section{[ TABLE 2 ]}

Nearly all type 1 patients consulted a specialist during the last year, as against three-quarters of type 2 patients. Those differences especially concern internists and ophthalmologists, the most consulted specialists in both groups. Six patients did not consult any physician.

Regarding the use of allied health care, about $30 \%$ of the patients had visited a dietitian and about $20 \%$ a physiotherapist during the last year. Patients diagnosed with type 1 diabetes were more likely to visit a podiatrist than patients with type 2 diabetes. About one quarter of the diabetic patients in both groups visited a pedicurist, which is higher than the number visiting a podiatrist.

The use of home care and complementary medicine was relatively high. More patients with type 1 diabetes than patients with type 2 diabetes consulted mental health care providers and diabetic nurses. Compared with the general population, both patient groups were more likely to be hospitalised. Almost all of them used prescribed medication, whereas only one third of the Dutch general population do so.

\subsection{Patterns of health care utilisation}

Only health care services consulted by $10-90 \%$ of the patients were included in this analysis, since the scores regarding health care workers that were consulted by hardly any patients (e.g. oral hygienist) or by nearly all patients (e.g. general practitioner) showed a lack of variance. Consequently, clustering was based on the following variables: number of GP contacts per year, contact with an internist, ophthalmologist, cardiologist, dietitian, physiotherapist, pedicurist, the use of home care and hospital admission.

Cluster analysis (see Table 3) revealed a fourcluster solution as the optimal number of clusters that could explain the profile structure of the patients' scores on health care utilisation variables.

\section{[ TABLE 3 ]}

Cluster $1(n=157)$ is the largest cluster, characterised by low use of health care services. Although these patients visit their GP on a regular basis, they seldom see other health care providers. None has seen an internist and only a quarter of them visit an ophthalmologist or dietitian. Contact with other health care workers, home care or hospital stays are uncommon. This pattern can be specified as the 'low consumption' pattern. Cluster $2(n=97)$ is the second largest group. These patients were all seen by an internist, whereas their number of GP contacts is somewhat lower than in the other clusters. Forty percent have visited an ophthalmologist and about a quarter consulted a pedicurist. Only $11 \%$ have seen a dietitian, the lowest percentage of the four clusters. Use of other health care services is also relatively low. This pattern is labelled the 'mainly internal medicine' pattern. Cluster $3(n=79)$ patients are characterised by relatively high percentages of patients having contact with the ophthalmologist, internist, dietitian, pedicurist and physiotherapist. A relatively large proportion have been hospitalised. Nevertheless, few patients have visited a cardiologist, and few receive home care. This pattern is named the 'extensive diabetes care' pattern. Cluster $4(n=55)$ is the smallest cluster, characterised by frequent contact with the GP and a large percentage of patients visiting a cardiologist and being hospitalised. The use of home care by these patients is relatively high. However, only half of them have visited an internist and the percentages visiting a dietitian or a physiotherapist are also relatively low. This pattern is referred to as the 'extensive medical care and home care' pattern.

\subsection{Predictors of health care utilisation patterns}

Since most patients belong to cluster 1 (low consumers), this cluster was taken as the reference category in the regression analysis. Thus, we assessed the likelihood of being assigned to the clusters 
2, 3 and 4 in comparison with cluster 1 on the basis of the scores on the independent variables. Table 4 shows the results of this analysis. Patients without social support at home, patients who have longer illness duration and patients with type 1 diabetes are likely to show the 'mainly internal medicine' consumption pattern. Lower educated patients and those who perceive their health as poor, are less likely to show the 'extensive diabetes care' pattern, whereas type 1 patients are far more likely to show this pattern than type 2 patients. Finally, patients who suffer from co-morbidity and patients who perceive their health as poor are more likely to show the 'extensive medical and home care' pattern than patients without co-morbidity and those who perceive a better general health.

\section{[ TABLE 4 ]}

\section{DISCUSSION}

Few studies exist in which the broad array of health care use among diabetic patients is investigated, and for the Netherlands no such data were available prior to this study. Diabetic patients in the Netherlands use a wide range of health care services. In general, type 1 diabetic patients visit more different health care providers than type 2 patients: more patients see internists, ophthalmologists, podiatrists, mental health care workers, and diabetic nurses. In contrast, type 2 patients see their GP more frequently than type 1 patients. According to the guidelines, a diabetic patient should consult a GP or an internist at least once a year. As we have seen, only six patients did not consult a physician in a 1-year period. However, regarding the prevention of complications, we may conclude that there is under use of other services. It is recommended that all diabetic patients undergo ophthalmologic examination at least once a year. In our sample, only $63 \%$ of the type 1 and $42 \%$ of the type 2 diabetic patients reported a yearly visit to an ophthalmologist. Although ophthalmologic examinations can be carried out by the GP, periodic examinations by an ophthalmologist are advised [35]. According to the International consensus on the diabetic foot, all diabetic patients should be examined at least once a year for potential foot problems [36]. Although GPs have a role in screening and education, foot care such as removal of callus and other foot and nail care should be provided by a certified pedicurist or podiatrist. Our study indicates that the majority of diabetic patients in the Netherlands do not receive preventive treatment by a podiatrist or pedicurist. A balanced composition of food is essential for metabolic regulation, and the guideline suggests that the dietitian has a central role in advice and assistance. Nevertheless, the majority of diabetic patients do not consult a dietitian. Unfortunately, we do not have a measure for obesity in this study. However, a recent study among Dutch type 2 diabetic patients showed a high prevalence of obesity [37]. In general, this study thus suggests that the care for diabetic patients in the Netherlands should be further improved.

Four patterns of health care utilisation could be distinguished based mainly on the heterogeneity of care received. Need factors were the best predictors of these health care utilisation patterns, a result which is preferred from a perspective of equal access: indeed Andersen considered access more equal, when health care use primarily is explained by differences in need, while access is considered as less equal, when merely explained by predisposing and/or enabling factors [30]. Type 1 diabetic patients most often showed the two intermediate patterns. Regarding the most extensive care pattern, the presence of co-morbid conditions, rather than diabetes type, was the best predictor. Poor perceived health was a predictor of the two most extensive care patterns (clusters 3 and 4), which is in line with the results of an extensive literature study into the causes and consequences of co-morbidity [38].

Of the predisposing factors, only educational level was related to the pattern of health care utilisation: diabetic patients with a low educational level are less likely to show the 'extensive diabetes care' pattern. Having social support at home was the only enabling factor contributing significantly: patients with social support at their disposal were four times more likely to show the "mainly internal medicine' pattern than patients without support at home. It is not clear how this result could be interpreted. Income and health care insurance had no predictive value for the health care utilisation pattern of diabetic patients, as might be expected from the organisation of health care in the Netherlands.

We do acknowledge some limitations of this study. We have no measure of obesity and no biomedical parameters such as $\mathrm{HbA}_{1 \mathrm{c}}$ and lipid levels. This limitation is the consequence of the general 
aim of the study, which is primarily directed at the consequences of chronic disease (psychosocial consequences, health care utilisation and quality of care as perceived by the patients). Thus, data collection has been directed at this type of information rather than at a detailed collection of epidemiological data.

Second, although we took into consideration comorbidity, for the same reason, this study cannot make a distinction between co-morbidity related to diabetes and other co-morbid disease.

Next, this study only considered factors related to the individual, which may influence health care use, while system delivery factors are not included. In particular, this study cannot provide insights into the reasons for the low use of ophthalmologists, pedicurist or podiatrist and dietitians: is this the consequence of the referral behaviour of the general practitioner or of non-compliance of the patient?

Finally, patients of a non-Dutch origin in general were excluded because their mastery of the Dutch language is insufficient. Nevertheless we know that their disease risk is sometimes higher and that the quality of care they receive in general is poorer. Thus, the relation we found between educational level and utilisation pattern may be an underestimation.

In conclusion, the data on the use of health care services in this study suggest under utilisation in some cases, especially in type 2 diabetic patients. This provides an explanation for the less than optimal diabetes-related health status as described in a recent study among Dutch type 2 diabetic patients [34]. Although most are under supervision of a medical doctor, usually the GP, more adequate use of other health care providers such as pedicurist or podiatrist, ophthalmologist and especially dietitian, could improve their health status. The results presented in this article are part of a policy study, characterised as a cohort studied repeatedly. As a policy study, these results are directly communicated to the Dutch government, and so they may serve as a basis for the development of new policy measures. As a cohort study, it will be possible to establish whether diabetes care in the Netherlands is improving and allow the evaluation of policy measures.

\section{ACKNOWLEDGEMENTS}

This study was performed within the research programme 'Panel of Patients with Chronic Diseases', which is financed by the Fund for Chronically Ill, the Ministry of Public Health, Welfare and Sports, the Inspectorate of Health Care, and the Ministry of Social Affairs and Employment of the Netherlands. We especially thank the patients willing to participate in this study. 
Fakiri, F. el, Foets, M., Rijken, M.

Health care use by diabetic patients in the Netherlands: patterns and predicting factors.

Diabetes Research and Clinical Practice: 61, 2003, p. 199-209

\section{TABLES}

Table 1

Description of the study population according to diabetes type

\begin{tabular}{|c|c|c|c|}
\hline & Type $1(N=134)$ & Type $2(N=254)$ & \\
\hline Gender $(\%)$ & $n=134$ & $n=251$ & \\
\hline Male:female & $54: 46$ & $49: 51$ & $\chi^{2}(1)=0.92, P=0.34$ \\
\hline Age (years) & $n=134$ & $n=251$ & \\
\hline Mean \pm S.D. & $49.8 \pm 16.6$ & $64.8 \pm 10.8$ & $t(194.66)=-9.42, P<0.001$ \\
\hline Educational level (\%) & $n=126$ & $n=243$ & \\
\hline Low & 17 & 23 & $\chi^{2}(3)=8.80, P=0.03$ \\
\hline Lower secondary & 44 & 53 & \\
\hline Higher secondary & 21 & 14 & \\
\hline Higher & 18 & 11 & \\
\hline Health care insurance $(\%)$ & $n=134$ & $n=253$ & \\
\hline Private:public & $34: 66$ & $31: 69$ & $\chi^{2}(1)=0.39, P=0.54$ \\
\hline Net income (per month per household) (\%) & $n=129$ & $n=225$ & \\
\hline Lower than $€ 840$ & 14 & 14 & $\chi^{2}(5)=2.72, P=0.74$ \\
\hline$€ 840-1.070$ & 17 & 24 & \\
\hline$€ 1.070-1.365$ & 13 & 14 & \\
\hline$€ 1.365-1.705$ & 21 & 18 & \\
\hline$€ 1.705-2.455$ & 23 & 19 & \\
\hline More than $€ 2.455$ & 12 & 11 & \\
\hline Availability of social support (\%) & $n=134$ & $n=254$ & \\
\hline Absent:present & $16: 84$ & $24: 76$ & $\chi^{2}(1)=3.36, P=0.07$ \\
\hline Diabetes duration (years) & $n=131$ & $n=248$ & \\
\hline Mean \pm S.D. & $14.5 \pm 0.7$ & $6.5 \pm 5.6$ & $t(168.88)=7.94, P<0.001$ \\
\hline Co-morbidity (\%) & $n=134$ & $n=254$ & \\
\hline Absent:Present & $78: 22$ & $72: 28$ & $\chi^{2}(1)=1.62, P=0.20$ \\
\hline Physical disability (\%) & $n=126$ & $n=228$ & \\
\hline Absent:present & $73: 27$ & $71: 29$ & $\chi^{2}(1)=0.23, P=0.63$ \\
\hline Perceived health (score 1-5) (\%) & $n=133$ & $n=249$ & \\
\hline Mean \pm S.D. & $2.7 \pm 0.7$ & $2.8 \pm 0.8$ & $t(380)=-0.61, P=0.54$ \\
\hline
\end{tabular}

Table 2

Health care utilisation of type 1 and type 2 diabetic patients

\begin{tabular}{|c|c|c|c|c|}
\hline & Type $1(N=134)$ & Type $2(N=254)$ & & General population ${ }^{\mathrm{a}}$ aged $>15$ years \\
\hline General practitioner & 94 & 96 & ns & 77 \\
\hline Medical specialist & 96 & 73 & $\chi^{2}(1)=30.36, P<0.001$ & 39 \\
\hline Internist & 81 & 35 & $\chi^{2}(1)=74.01, P<0.001$ & \\
\hline Ophthalmologist & 63 & 42 & $\chi^{2}(1)=15.41, P<0.001$ & \\
\hline Cardiologist & 11 & 16 & ns & \\
\hline Surgeon & 13 & 9 & ns & \\
\hline Neurologist & 9 & 7 & ns & \\
\hline Other medical specialist & 39 & 35 & ns & \\
\hline \multicolumn{5}{|l|}{ Allied health care } \\
\hline Dietitian & 30 & 28 & $\mathrm{~ns}$ & \\
\hline Physiotherapist & 21 & 19 & ns & 15 \\
\hline Podiatrist & 13 & 7 & $\chi^{2}(1)=3.89, P<0.05$ & \\
\hline Oral hygienist & 6 & 5 & ns & \\
\hline Occupational therapist & 1 & 1 & ns & \\
\hline Exercise therapist & 0 & 1 & ns & \\
\hline Other allied health care & 1 & 0 & ns & \\
\hline \multicolumn{5}{|l|}{ Other (health care) services } \\
\hline Pedicurist & 27 & 27 & ns & \\
\hline Mental health care & 9 & 4 & $\chi^{2}(1)=4.88, P<0.05$ & \\
\hline Complementary medicine & 12 & 7 & ns & 7 \\
\hline Home care & 15 & 12 & ns & 4 \\
\hline Diabetic nurse & 7 & 2 & $\chi^{2}(1)=4.48, P<0.05$ & \\
\hline Hospital stay & 26 & 20 & ns & 6 \\
\hline Prescribed medication & 94 & 95 & ns & 37 \\
\hline
\end{tabular}

Data are $\%$ of total group.

a Source: Statistics Netherlands, unpublished data, 1998. 
Fakiri, F. el, Foets, M., Rijken, M.

Health care use by diabetic patients in the Netherlands: patterns and predicting factors.

Diabetes Research and Clinical Practice: 61, 2003, p. 199-209

Table 3

Description of diabetes clusters according to health care utilisation

\begin{tabular}{lllll}
\hline & Cluster 1 $(n=157)$ & Cluster 2 $(n=97)$ & Cluster 3 $(n=79)$ & Cluster $4(n=55)$ \\
\hline $\begin{array}{l}\text { GP contacts per year (mean } \pm \text { S.D.) } \\
\text { Contact } \text { with (\%) }\end{array}$ & $5.0 \pm 3.7$ & $4.4 \pm 4.8$ & $5.6 \pm 4.5$ & $7.3 \pm 7.9$ \\
Internist & 0 & 100 & 92 & 53 \\
Ophthalmologist & 27 & 40 & 90 & 69 \\
Cardiologist & 3 & 1 & 4 & 87 \\
Dietitian & 25 & 11 & 66 & 17 \\
Physiotherapist & 13 & 4 & 51 & 24 \\
Pedicurist & 18 & 28 & 35 & 38 \\
Home care & 7 & 12 & 13 & 31 \\
Hospital stay (\%) & 3 & 8 & 41 & 68 \\
\hline
\end{tabular}

Table 4

Results of multinomial logistic regression analysis predicting cluster membership (cluster 1 is the reference category)

\begin{tabular}{llll}
\hline & Cluster 2 $\operatorname{Exp}(\mathrm{B}) \mathrm{CI}$ & Cluster 3 $\operatorname{Exp}(\mathrm{B}) \mathrm{CI}$ & Cluster $4 \operatorname{Exp}(\mathrm{B}) \mathrm{CI}$ \\
\hline $\begin{array}{l}\text { Predisposing factors } \\
\text { Gender }\end{array}$ & $\mathrm{ns}$ & $\mathrm{ns}$ & $\mathrm{ns}$ \\
Age & $\mathrm{ns}$ & $\mathrm{ns}$ & $\mathrm{ns}$ \\
$\begin{array}{l}\text { Educational level (ref: higher) } \\
\text { Low }\end{array}$ & $\mathrm{ns}$ & $0.23(0.05-0.99), P=0.048$ & $\mathrm{~ns}$ \\
Enabling factors & & & \\
Health care insurance & $\mathrm{ns}$ & $\mathrm{ns}$ & $\mathrm{ns}$ \\
Net income & $\mathrm{ns}$ & $\mathrm{ns}$ & $\mathrm{ns}$ \\
Availability of support & $4.74(1.48-15.15), P=0.009$ & $\mathrm{~ns}$ & $\mathrm{~ns}$ \\
Need factors & & & \\
Illness duration & $1.05(1.00-1.10), P=0.048$ & $\mathrm{~ns}$ & $\mathrm{~ns}$ \\
Co morbidity & $\mathrm{ns}$ & $\mathrm{ns}$ & $2.48(1.01-6.07), P=0.048$ \\
Physical disability & $\mathrm{ns}$ & $\mathrm{ns}$ & $\mathrm{ns}$ \\
Perceived health & $\mathrm{ns}$ & $0.55(0.32-0.95), P=0.031$ & $0.49(0.26-0.92), P=0.026$ \\
Diabetes type (type 1) & $4.09(1.62-10.34), P=0.003$ & $5.41(2.11-13.86), P=0.000$ & $\mathrm{~ns}$ \\
\hline
\end{tabular}

Data are expressed as odd ratio ( $95 \%$ confidence intervals); ns, non-significant.

\section{REFERENCES}

[1] A.F. Amos, D.J. McCarthy, P. Zimmet, The rising global burden of diabetes and its complications: estimates and projections to the year 2010, Diabetic Med. 14 (Suppl) (1997) S1-85.

[2] H. King, R.E. Aubert, W.H. Herman, Global burden of diabetes, 1995-2025: prevalence, numerical estimates, and projections, Diabetes Care 21 (1998) 1414-1431.

[3] D. Ruwaard, R.A. Hirasing, H.M. Reeser, et al., Increasing incidence of type 1 diabetes in the Netherlands: the second nation-wide study among children under 20 years of age, Diabetes Care 17 (1994) 599-601.

[4] W.J.C. de Grauw, E.H. van den Lisdonk, H.J.M. van den Hoogen, et al., Cardiovascular morbidity and mortality in type 2 diabetic patients: a 22-year historical cohort study in Dutch general practice, Diabetic Med. 12 (1995) 117-122.

[5] P.J. Beks, A.J.C. Mackaay, J.N.D. de Neeling, et al., Peripheral arterial disease in relation to glycaemic level in an elderly Caucasian population: the Hoorn Study, Diabetologica 38 (1995) 86-89.

[6] R. Klein, Hyperglycemia and microvascular and macrovascular disease in diabetes, Diabetes Care 18 (1995) 258-268.

[7] D. Ziegler, F.A. Gries, M. Spuler, et al., The epidemiology of diabetic neuropathy, Diabetic Med. 10 (Suppl.) (1993) S82-S86.

[8] G.E.H.M. Rutten, S. Verhoeven, R.J. Heine, et al., NHGStandaard Diabetes Mellitus Type 2 (first revision), Huisarts Wet 42 (1999) 67-84.

[9] P.M. Jonsson, L. Nystrom, U. Rosenqvist, et al., Diabetes mellitus and health service utilization: a case-control study of outpatient visits 8 years after diagnosis, Diabetic Med. 13 (1996) 1056-1063.

[10] M.W. Knuiman, T.A. Welborn, H.C. Bartholomew, Selfreported health and use of health services: a comparison of diabetic and non-diabetic persons from a national sample, Aust. New Zealand J. Public Health 20 (1996) 241-247. 
Fakiri, F. el, Foets, M., Rijken, M.

Health care use by diabetic patients in the Netherlands: patterns and predicting factors.

Diabetes Research and Clinical Practice: 61, 2003, p. 199-209

[11] P.E. Wandell, B. Brorsson, H. Aberg, Drug use in patients with diabetes, Diabetes Care 19 (1996) 992-994.

[12] S. Aro, T. Kangas, A. Reunanen, M. Salinto, V. Koivisto, Hospital use among diabetic patients and the general population, Diabetes Care 17 (1994) 1320-1329.

[13] M.I. Harris, Diabetes in America: epidemiology and scope of the problem, Diabetes Care 21 (Suppl. 3) (1998) C11-C14.

[14] C.A. McCarty, C.W. Lloyd-Smith, S.E. Lee, P.M. Livingston, Y.L. Stanislavsky, H.R. Taylor, Use of eye care services by people with diabetes: the Melbourne Visual Impairment Project, Br. J. Ophtalmol. 82 (1998) 410-414.

[15] S.B. Laditka, M.P. Mastanduno, J.N. Laditka, Health care use of individuals with diabetes in an employer-based insurance population, Arch. Intern. Med. 161 (2001) 1301-1308.

[16] J.B. Saaddine, M.M. Engelgau, G.L. Beckles, E.W. Gregg, T.J. Thompson, K.M. Narayan, A diabetes report card for the United States: quality of care in the 1990s, Ann. Intern. Med. 136 (2002) 565-574.

[17] A.K. Fletcher, J. Dolben, A hospital survey of the care of elderly patients with diabetes mellitus, Age Ageing 25 (1996) 349-352.

[18] M.I. Harris, Racial and ethnic differences in health care access and health outcomes for adults with type 2 diabetes, Diabetes Care 24 (2001) 454-459.

[19] P.M. Jonsson, G. Sterky, C. Gafvels, J. Ostman, Gender equity in health care: the case of Swedish diabetes care, Health Care Women Int. 21 (2000) 413-431.

[20] L.A. Panser, J.M. Naessens, F.T. Nobrega, et al., Utilization trends and risk factors for hospitalization in diabetes mellitus, Mayo Clin. Proc. 65 (1990) 1171-1184.

[21] T. Robson, D. Blakwell, C. Waine, R.L. Kennedy, Factors affecting the use of dietetic services by patients with diabetes mellitus, Diabetic Med. 18 (2001) 295-300.

[22] M.M. Engelgau, L.S. Geiss, D.L. Manninen, et al., Use of services by diabetes patients in managed care organizations. Development of a diabetes surveillance system, Diabetes Care 21 (1998) 2062-2068.

[23] G.I. Beckles, M.M. Engelgau, K.M. Narayan, W.H. Herman, R.E. Aubert, D.F. Williamson, Population-based assessment of the level of care among adults with diabetes in the US, Diabetes Care 21 (1998) 1432-1438.

[24] C.A. Smith, K.A. Wallston, Adaptation in patients with chronic rheumatoid arthritis: application of a general model, Health Psychol. 11 (1992) 151-162.

[25] C. Wagner, M. Foets, L. Peters, J. Dekker, Haalbaarheidsstudie patie"nten panel chronisch zieken, Projectvoorstel en verslag haalbaarheidsstudie Utrecht: Nivel 1996.

[26] P.M. Rijken, M. Foets, L. Peters, A.F. de Bruin, J. Dekker, Patie"ntenpanel Chronisch Zieken, Kerngegevens 1998, Utrecht: Nivel 1999.

[27] H.J. Sixma, J.J. Kerssens, C.V. van Campen, L. Peters, Quality of care from the patients' perspective: from theoretical concept to a new measuring instrument, Health Expect. 1 (1998) 82-95

[28] J. Cohen, Statisitcal Power Analysis for the Behavioural Sciences, Laurence Erlbaum Associates Publishers, Hillsdale NJ, 1988.

[29] H. Swinkels, Het meten van medische consumptie met behulp van enque tes, in: R. Sanderman, C.M.H. Hosman, M. Mulder (Eds.), Het meten van determinanten van gezondheid: een overzicht van beschikbare meetinstrumenten, Van Gorcum, Assen, 1995, pp. 332-357.

[30] R.M. Andersen, Revising the behavioural model and access to medical care: does it matter, J. Health Social Behav. 36 (1995) 1 -10.

[31] H. Lamberts, M. Wood, ICPC International Classification of Primary Care, Oxford University Press, Oxford, 1987.

[32] J.R. McWinnie, Disability assessment in population surveys: results of the O.E.C.D. common development effort, Revue d, Epide' miologie et de Sante' Publique 29 (1981) 413-419.

[33] M.J. Norusis, SPSS/PC+ Professional statistics-Version 5, SPSS Inc., Chicago, 1992.

[34] SPSS Regression models 9.0, SPSS Inc., Chicago, 1999.

[35] G.P.J.M. Konings, D. Wijkel, G.E.H.M. Rutten, Lukt het werken volgens de NHG-Standaard Diabetes mellitus type II, Huisarts Wetenschap 38 (1995) 10-14.

[36] International Working Group on the Diabetic Foot, International consensus on the diabetic foot, Amsterdam, 1999.

[37] M. Bouma, J.H. Dekker, J.H.T. van Eijk, F.G. Schellevis, D.M.W. Kriegsman, R.J. Heine, Metabolic control and morbidity of Type 2 diabetic patients in a general practice network, Family Pract. 16 (1999) 402-406.

[38] R. Gijsen, N. Hoeymans, F.G. Schellevis, D. Ruwaard, W.A. Satariano, G. van den Bos, Causes and consequences of comorbidity; a review, J. Clin. Epidemiol. 54 (2001) 661-674. 